Research Article

\title{
Assessment of AAR and Sulfate Attack on Wadi Gravel Concrete after 4 Years in Service
}

\author{
Khaled Hassan ${ }^{1,{ }^{+},{ }^{*}, \text { Ian Sims }}{ }^{2,{ }^{\dagger}}$, Murray Reid ${ }^{3,}{ }^{+}$, Alex Smith ${ }^{2}$, Mohammed Al-Kuwari ${ }^{4}$
}

1. Infrastructure Research and Development (IRD QSTP-LLC), Doha, Qatar; E-Mail: khassan@irdme.net

2. RSK Environment Ltd, Hemel Hempstead, UK; E-Mails: isims@rsk.co.uk; asmith@rsk.co.uk

3. Infrastructure Research and Development (IRD QSTP-LLC), Glasgow, UK; E-Mail: murray54jmr@hotmail.co.uk

4. Ministry of Municipality and Environment, Doha, Qatar; E-Mail: $\underline{\text { msakuwari@mme.gov.qa }}$

$\dagger$ These authors contributed equally to this work.

* Correspondence: Khaled Hassan; E-Mail: khassan@irdme.net

Academic Editor: Paulina Faria

Special Issue: Wastes, Residues and Byproducts for the Production of Construction Materials

Recent Progress in Materials

2021, volume 3 , issue 3

doi:10.21926/rpm.2103038
Received: April 18, 2021

Accepted: September 15, 2021

Published: September 26, 2021

\begin{abstract}
Wadi gravel is a local aggregate in Qatar that could contribute to enhanced sustainability by replacing expensive imported gabbro. The material needs to be processed before use to reduce sulfate content to acceptable levels. The paper presents the performance assessment of three full-scale buildings, variously made with $50 \%$ and $100 \%$ Wadi gravel and conventional gabbro concretes. Site monitoring up to four years in service demonstrated the strength development with age and resistance to the aggressive exposure conditions in Qatar. The Wadi gravel concrete exhibited at least similar performance to the gabbro concrete, and excellent durability as defined in national construction specifications. The paper provides initial long-term assessment and builds on previous publications by the authors, for initial assessment of Wadi gravel concrete.
\end{abstract}

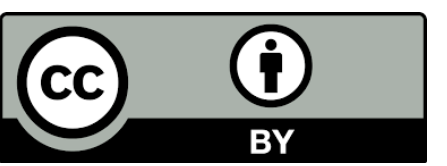

(C) 2021 by the author. This is an open access article distributed under the conditions of the Creative Commons by Attribution License, which permits unrestricted use, distribution, and reproduction in any medium or format, provided the original work is correctly cited. 
In an earlier investigation by the authors, a difference was observed between the concrete prism expansion test results of RILEM AAR-4.1 and BS 812-123. Wadi gravel was classified as potentially reactive in the more accelerated RILEM AAR-4.1 and of low reactivity in the more realistic exposure BS 812-123. Petrographic examination of the hardened concrete after four years in service has shown no evidence of cracking or signs of distress or deterioration and confirmed the BS 812-123 interpretation of alkali-silica reactivity of Wadi gravel concrete. The results obtained in this investigation provide more confidence for the wider and efficient use of Wadi gravel in structural concrete.

\section{Keywords}

Alkali-silica reaction; concrete; durability; expansion; long-term; performance; Wadi gravel

\section{Introduction}

Qatar is a small state that occupies a peninsula on the Arabian Gulf adjacent to Bahrain, the Kingdom of Saudi Arabia (KSA) and the United Arab Emirates (UAE). Like other states in the region, it has undergone a major programme of development in recent decades. The rapidly developing infrastructure is based upon a Qatari government commitment to maintain a balance between development needs and protection of the environment [1].

Construction in hot desert environments such as Qatar faces a number of challenges, including the lack of natural resources, consequently relying on imports, and aggressive exposure environments, posed by excessive heat and humidity for large parts of the year, aggressive ground conditions with potentially high sulfate and chloride contents and a high groundwater table [2-4]. Aggregate is needed for the mega infrastructure projects; however, Qatar lacks indigenous quality aggregate materials. Most of the peninsula is underlain by relatively weak limestones of Eocene age, which often contain beds of potentially expansive clays and gypsum [5]. Local limestone is used in unbound construction applications of subbase, pipe bedding and fill, but not in structural concrete [6]. Qatar therefore presently relies on imported aggregate for concrete and asphalt applications. The principal imported aggregate is gabbro, a coarse-grained igneous rock, which is currently obtained from Oman, several hundred kilometres to the east.

Potential local sources of coarse aggregate for use in concrete are a few deposits of sand and gravel which are present on the higher parts of the peninsula south west of the capital, Doha. The sand and gravel deposits are part of the Hofuf Formation of Upper Miocene to Pliocene age, which consists of river-lain sand and gravel deposits. The gravel content of the deposits is generally fairly low, in the range of $10 \%$ to $20 \%$ and consists of a range of rock types, including igneous and metamorphic rocks from the Arabian Shield and limestone and other sedimentary rocks from the Arabian Shelf, thought to have been transported by large river systems. Similar deposits are found widely in Eastern KSA and other areas in the region [7]. These sand and gravel deposits are generally known as "Wadi gravel".

Use of Wadi gravel as aggregate has hitherto been limited by the fact that the deposits are extensively cemented by gypsum (Figure 1), a sulfate mineral $\left(\mathrm{CaSO}_{4} \cdot 2 \mathrm{H}_{2} \mathrm{O}\right)$. Where the deposits are uncemented, they have been extensively worked for fine aggregate for concrete, with the excavated 
material being washed and processed to remove clay and salt and also oversize $(>4 \mathrm{~mm})$ material. This oversize material is then dumped in the old workings, which thus contain a mix of original natural strata with high gypsum content and dumped oversize material. The oversize material contains a much higher percentage of gravel than the original strata, but the challenge of separating the aggregate from the gypsum has prevented the exploitation of the material for coarse aggregate in concrete. Conventional processing by crushing and sieving is not sufficient to remove the gypsum completely (Figure 2).

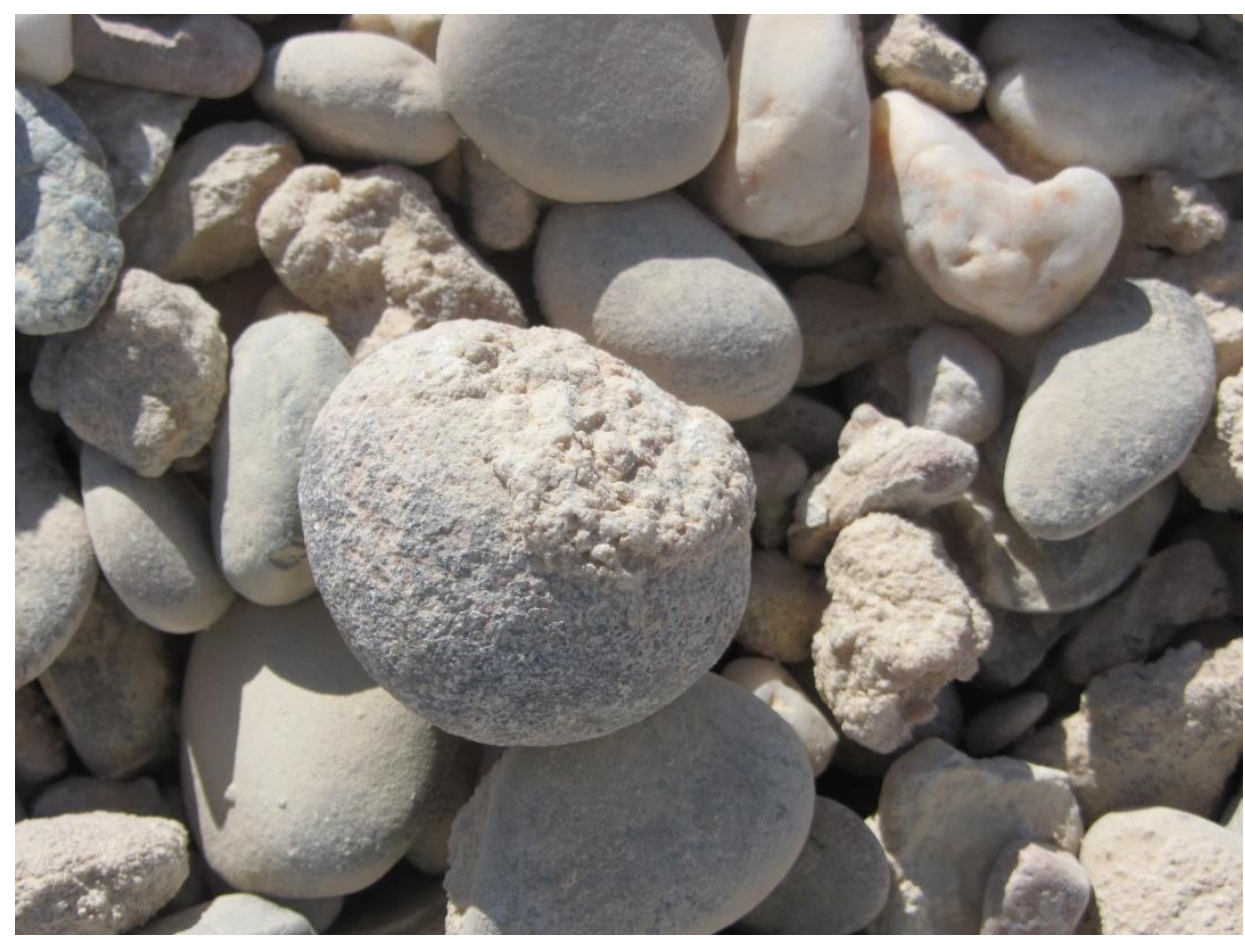

Figure 1 Wadi gravel cemented by gypsum.

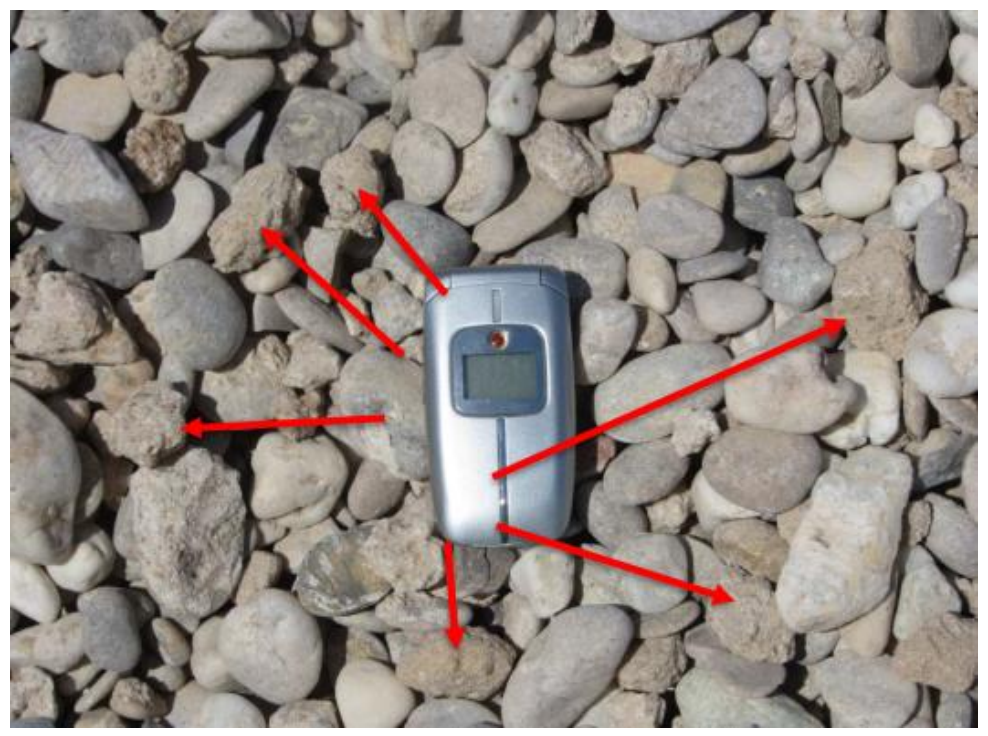

Figure 2 Wadi gravel subjected to simple crushing and screening still contains large quantities of gypsum bound deposits (Examples of gypsum-bound deposits shown by red arrows). 
The Qatar Construction Specifications, QCS 2014 [8] set very strict limits for sulfate content of aggregates for use in concrete, which the as-dug or crudely processed Wadi gravel in Figure 1 and Figure 2 would not meet. This is to prevent the formation within concrete of the expansive mineral ettringite $(\mathrm{CaO})_{3}\left(\mathrm{Al}_{2} \mathrm{O}_{3}\right)\left(\mathrm{CaSO}_{4}\right)_{3} .32 \mathrm{H}_{2} \mathrm{O}$, which forms from the reaction of calcium aluminium hydrate in the cement with sulfate from the gypsum and water, and results in cracking and disruption of the concrete $[3,4]$. In hot desert environments it can be very difficult to find sources of aggregate that do not contain high concentrations of sulfate, chloride and other salts, which can cause disruption to concrete through expansive reactions and/or corrosion of reinforcement. Fresh igneous or metamorphic rocks, such as gabbro, sourced from mountainous areas such as Oman and the UAE, are thus the best aggregates available in the region and are widely used, despite the long transport distances.

Such long transport distances for bulk materials such as aggregates, however, add considerably to the cost and the carbon footprint of the resulting concrete [6]. Research was therefore carried out to determine if it would be possible to process local Wadi gravel to reduce the sulfate content to an acceptable level and produce aggregate that met the requirements of the QCS 2014 for coarse aggregate in concrete [7]. The project found that satisfactory aggregate could be produced by multistage processing using advanced crushing and washing techniques. A laboratory testing programme demonstrated that satisfactory mixtures for structural concrete could be produced using the Wadi gravel, either as the sole coarse aggregate or blended 50:50 with imported gabbro.

A further concern with using gravel containing a number of different rock types as aggregate in concrete is the possibility of Alkali-Silica Reaction (ASR), which could lead to cracking and disruption of the concrete in the long term. A detailed laboratory investigation into this aspect was carried out [9], including accelerated laboratory tests using a variety of techniques. The tests were carried out using the same mixtures used for the laboratory trials and concluded that the Wadi gravel could be safely used as coarse aggregate in structural concrete either as a 50:50 blend with imported gabbro or with the use of cement replacement materials such as ground granulated blastfurnace slag (ggbs) or coal fly ash (FA).

In order to validate the results of the laboratory tests and demonstrate that Wadi gravel could be used in a practical context as coarse aggregate in concrete, a field trial was carried out at the site of the largest deposit of Wadi gravel near Mekaines, in the south of Qatar. Three trial buildings were successfully constructed in June 2016, using Wadi gravel as coarse aggregate in concrete blocks and structural concrete. The buildings were inspected visually on a regular basis, and cores were taken for testing after one year. In 2020 a further set of cores was taken. This paper describes the results of the testing and visual inspections and provides an initial evaluation of the longer-term performance of the Wadi gravel concrete after four years exposure to a harsh desert environment. The trials will be maintained, and further evaluation is planned at later ages.

\section{Materials and Methods}

\subsection{Concrete Ingredients and Mix Design}

\subsubsection{Portland Cement}

Portland cement (PC) was supplied by Qatar National Cement Company (QNCC) and complied with the QCS 2014 requirements and BS EN 197-1 [10], minimum grade of 42.5. The QNCC cement 
was used for the construction of building trials. Portland cements with higher alkali contents were used for the alkali-silica reaction (ASR) expansion testing, as explained later.

\subsubsection{Aggregate}

The Wadi gravel was obtained from the Mekaines site, in the south west of Qatar, approximately $50 \mathrm{~km}$ from Doha, and processed using the multistage treatments described in [7]. The imported gabbro aggregate was supplied by Gulf Rocks Co. in the UAE. The fine aggregate was a local washed sand and was supplied by QNCC. Local sand is generally washed before use in concrete for the removal of fine particles that contain gypsum and clay. The coarse and fine aggregates were tested for compliance with the QCS 2014 requirements for use in concrete.

\subsubsection{Mixing Water and Chemical Admixture}

Potable water, complying with the QCS 2014 requirement, was used for concrete mixing. The chemical admixture was a superplasticiser based on modified synthetic carboxylated polymers, Epsoline HP 520, supplied by Sodamco.

\subsubsection{Mix Design}

A typical C40 mix, which has a characteristic compressive strength of $40 \mathrm{MPa}$ in cubes cured in water at $20^{\circ} \mathrm{C}( \pm 2)$ and tested at 28 days after casting, was used for production of the concrete mixtures. This mix is widely used by the ready-mix plants in Qatar; in this case, the mix was produced at the Al-Ghurair ready mix plant. Table 1 gives the weight compositions of the 3 concrete mixtures considered in this investigation; a conventional $100 \%$ gabbro concrete, plus $50 \%$ and $100 \%$ Wadi gravel concretes. The Wadi gravel was used to replace $50 \%$ and $100 \%$ by volume of gabbro. The mixing water was maintained at a constant $\mathrm{w} / \mathrm{c}$ ratio of 0.42 for all mixtures, and the amount of superplasticiser was adjusted to achieve a target slump of $200 \mathrm{~mm}( \pm 20)$ at the production unit, and to maintain $100 \mathrm{~mm}$ minimum on arrival at site, measured in accordance with BS EN 12350-2 [11]. Table 1 shows that the higher content of Wadi gravel in the concrete reduces the superplasticiser dosage required to achieve the same slump as the gabbro concrete. This could probably be attributed to the more rounded particles of Wadi gravel aggregate that contribute to improved workability.

Table 1 Mix compositions-trial building mixtures.

\begin{tabular}{llll}
\hline Material & $100 \%$ Gabbro & $50 \%$ Wadi gravel & $100 \%$ Wadi gravel \\
\hline Portland cement, $\mathrm{kg} / \mathrm{m}^{3}$ & 340 & 340 & 340 \\
Water, $\mathrm{l} / \mathrm{m}^{3}$ & 143 & 143 & 143 \\
Gabbro, $\mathrm{kg} / \mathrm{m}^{3}$ & 1197 & 598 & - \\
Wadi gravel, $\mathrm{kg} / \mathrm{m}^{3}$ & - & 553 & 1106 \\
Washed sand, $\mathrm{kg} / \mathrm{m}^{3}$ & 835 & 835 & 835 \\
Super plasticiser, $\mathrm{l} / \mathrm{m}^{3}$ & 5.90 & 5.30 & 4.60 \\
\hline
\end{tabular}




\subsection{Alkali-Silica Reaction}

The alkali-silica reaction (ASR) testing programme comprised petrographic examination; accelerated screening tests; and longer-term expansion tests. Petrographic analysis to BS 812: 104 [12] was conducted on the Wadi gravel to identify the main constituent rock types.

The accelerated mortar-bar method of expansion testing for the potential alkali-reactivity of aggregates was conducted in accordance with ASTM C1260 [13]. Three mortar mixtures were tested to include $100 \%$ gabbro, $50 \%$ Wadi gravel and $100 \%$ Wadi gravel. Results of the accelerated mortarbar mixtures are presented elsewhere [9].

The long-term concrete prism tests were conducted on 3 concrete mixtures, using the RILEM AAR-4.1 [14] and BS 812:123 [15] test methods. The BS concrete prism testing takes a relatively long time ( 52 weeks), by comparison with the accelerated AAR-4.1 tests ( 20 weeks) but is considered probably to be more realistic at representing typical behaviour of aggregate materials used in the field. A comparison of the test conditions for both RILEM AAR-4.1 and BS 812:123 test methods is summarised in Table 2.

Table 2 Comparison between RILEM AAR-4.1 and BS 812:123 test conditions.

\begin{tabular}{lll}
\hline Parameter & RILEM AAR-4.1 & BS 812:123 \\
\hline Test duration (weeks) & 20 & 52 \\
Alkali content (\% Na${ }_{2} \mathrm{O}$ equiv.) & 1.3 & 0.8 \\
Storage temperature $\left({ }^{\circ} \mathrm{C}\right)$ & 60 & 38 \\
Relative humidity $(\%)$ & 100 & 96 \\
Container type & Sealable containers & Sealable containers \\
\hline
\end{tabular}

Coarse aggregate of Wadi gravel and gabbro, together with washed sand as fine aggregate, from the same sources later used for the building trials, were used in the mixtures. Storage conditions varied between the two tests. RILEM AAR-4.1 concrete prisms were exposed to $60^{\circ} \mathrm{C}$ temperatures at as close as possible to $100 \%$ relative humidity $(\mathrm{RH})$, whereas BS 812-123 concrete prisms were exposed to humidity $>96 \% \mathrm{RH}$ at $38^{\circ} \mathrm{C}$ [9].

\subsection{Building Trials}

\subsubsection{Construction of Trial Buildings}

Following the completion of the ASR laboratory investigation, three trial buildings were constructed at the Mekaines site, each with the cross section of $4.0 \mathrm{~m} \times 4.0 \mathrm{~m}$ and one storey height of $3.85 \mathrm{~m}$. Each building was constructed with one of the mixtures given in Table 1 . The construction of the three buildings was conducted in parallel with one truck for each concrete mix delivered on the same day of casting. Four structural elements were cast for each building:

- Foundations

- Ground and neck beams

- Columns and a control beam

- Roof beams and slabs 
Additional beams, with dimensions of $4.0 \times 0.5 \times 0.2 \mathrm{~m}$, were cast from the same batches used for the concrete columns and stored separately behind each building. The additional beams were partially buried within the fill material around the buildings, Figure 3, and were later used for coring and testing the different concrete mixtures at different ages. The purpose was to represent aggressive ground conditions and excessive heat near the ground surface [7].

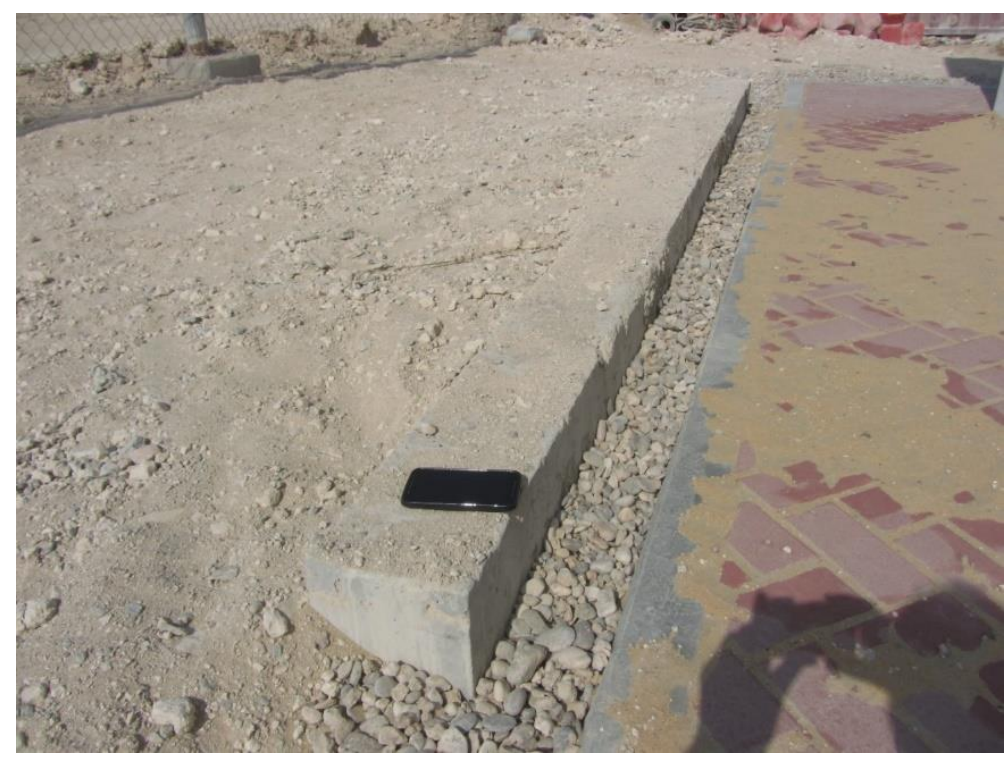

Figure 3 Additional beam cast for coring and long-term monitoring behind buildings.

Construction took place in the summer of 2016 (June/July), with an average air temperature in the range of $40^{\circ} \mathrm{C}$ to $50^{\circ} \mathrm{C}$. The QCS 2014 requires that the temperature of concrete on delivery shall not exceed $32^{\circ} \mathrm{C}$. This was achieved using chilled water for concrete mixing and also for pre-cooling the truck-drum prior to loading the fresh concrete. Testing of concrete slump, as per BS EN $12350-$ 2 [11], was conducted on arrival at site, approximately 75 min drive from the plant. Figure 4 and Figure 5 show the site monitoring of concrete temperature and slump, respectively. As part of controlling the quality of ready-mix concrete used for different batches, cubes (150mm sides) were prepared from each batch and cured in a water tank at $20^{\circ} \mathrm{C}( \pm 2)$. The cubes were tested for compressive strength at the ages of 7 and 28 days, in accordance with BS EN 12390-3 [16]. Three cubes were used for each test and the average value was reported. 


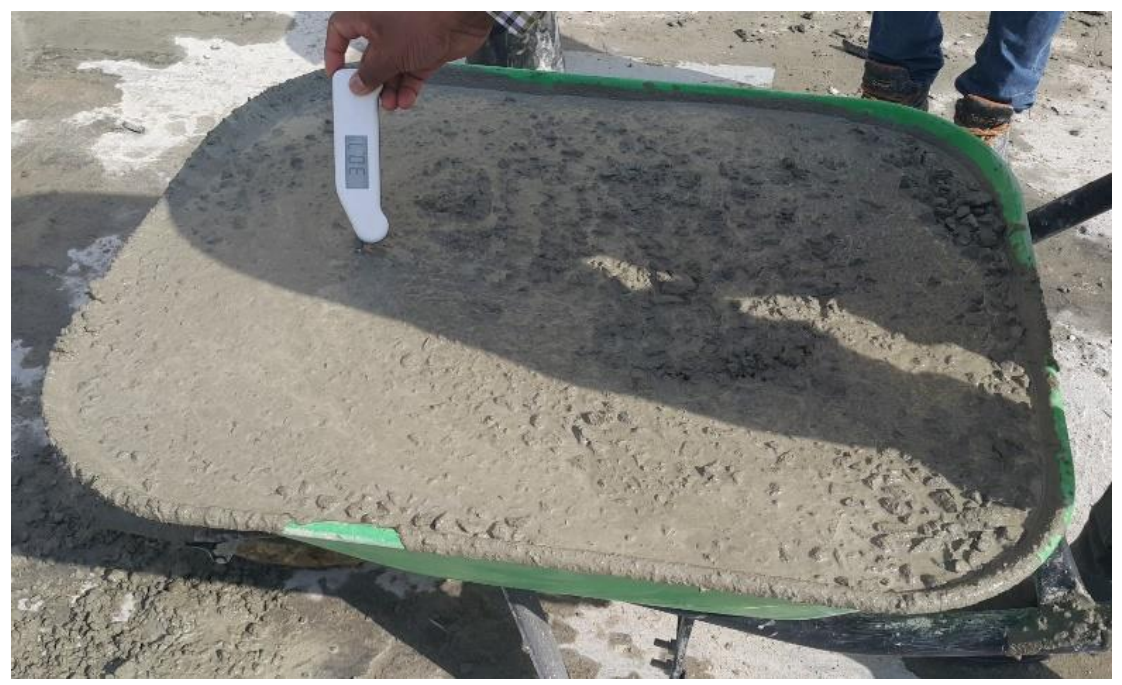

Figure 4 Measuring concrete temperature on site.

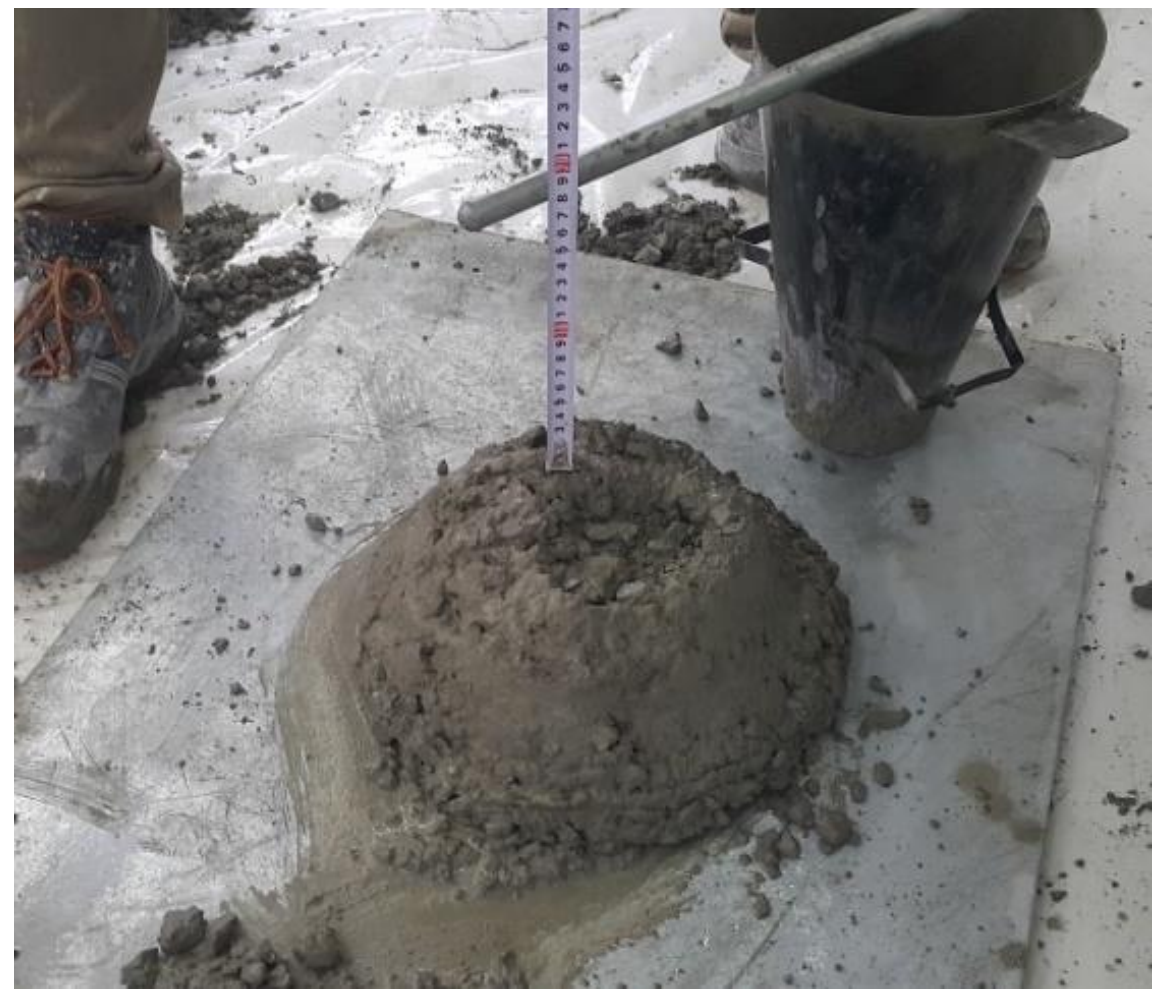

Figure 5 Measuring concrete slump on site.

Performance assessment of the building trials was made through periodic visual inspection and core testing up to 4 years in service. At the age of testing, the beams were removed from the ground for coring and then reinstalled again for long-term monitoring. Cores were taken from the beams behind the buildings, and immediately wrapped with Cling film and sealed in plastic bags until testing, Figure 6. Core compressive strength, to BS EN 12504-1 [17], and water absorption to BS 1881-122 [18] were used for the durability assessment as per the QCS 2014. For each test, at any specific age, three cores of $100 \mathrm{~mm}$ diameter and $100 \mathrm{~mm}$ height were tested for strength and 75 $\mathrm{mm}$ diameter and $100 \mathrm{~mm}$ height were tested for water absorption. 


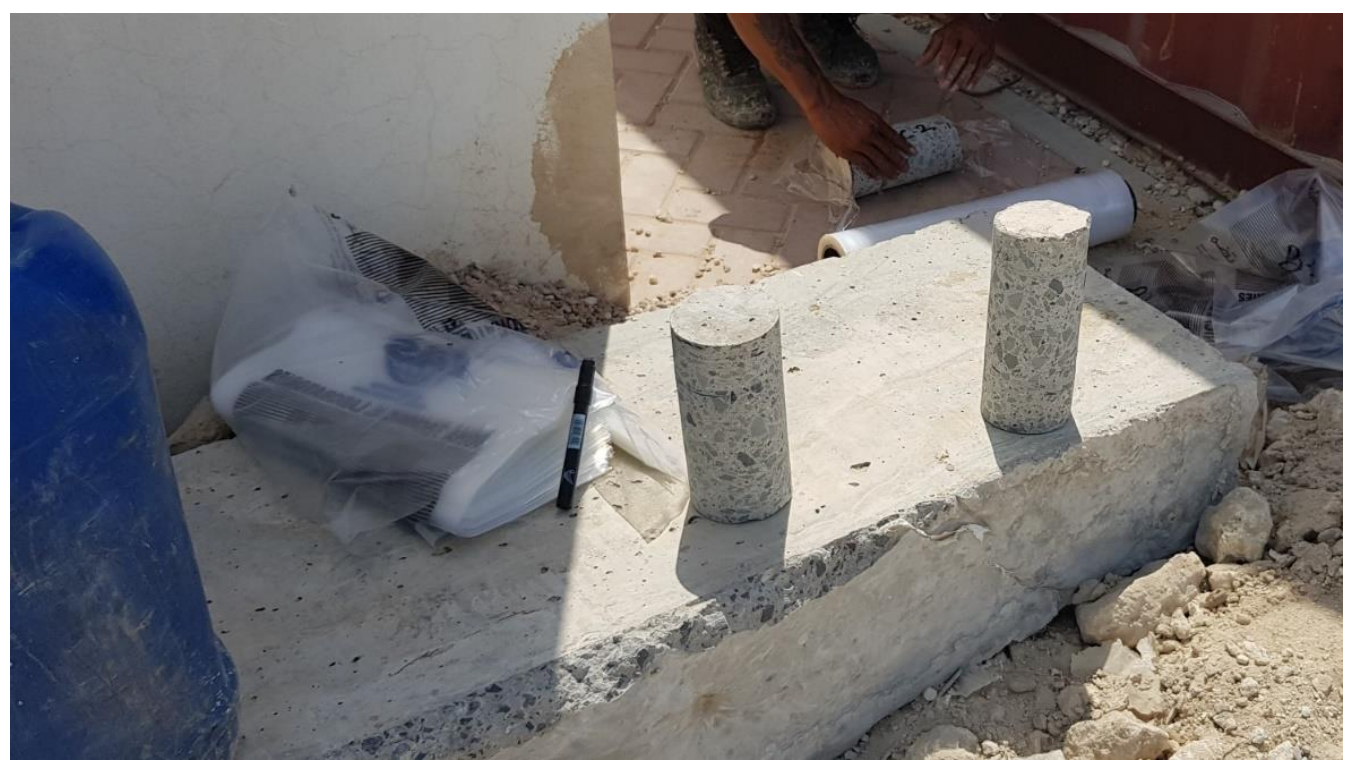

Figure 6 Coring and sealing of the core specimens.

\subsubsection{Soil and Concrete Testing}

High salts concentration in soil may cause serious problems for reinforced concrete structures. Soil samples were collected from the excavated materials (limestone) for the building trials and tested for chloride and sulfate content as per BS 1377-3 [19] (currently BS 1377-3: 2018). Two soil samples, obtained at mid-depth of excavated limestone material, were tested and the average values were reported. Cores were also taken from the test beams after 4 years exposure to ground conditions and subjected to petrographic analyses to assess any evidence of potential detrimental ASR and/or sulfate attack reactions.

The petrographic examination of the cores was conducted following methods recommended by ASTM C856-18 [20]. Estimation of 'excess voidage' was carried out in accordance with BS EN 125041 [17]. Visual inspection of the cores was used to determine the most appropriate location for preparation of a medium-area $(45 \times 30 \mathrm{~mm})$ thin section, taken for further, more detailed microscopical examination, employing various magnifications up to $\times 630$. The thin sections were examined variously using transmitted, plane-polarised and cross-polarised illuminations. Additional examination under reflected ultraviolet illumination allowed an assessment of the void and micropore structures, evidence of any cracking and other relevant features. Testing and petrographic examination were conducted by RSK-UK in their UKAS-accredited laboratory (RSK, 2020).

\section{Results}

\subsection{Aggregate Properties and Compliance}

The properties of coarse and fine aggregates are given in Table 3, together with the specified limits of the Qatar Construction Specifications (QCS 2014). Wadi gravel and gabbro aggregates satisfied the QCS 2014 requirements for use as coarse aggregate in concrete. Wadi gravel had higher fines content (passing $0.063 \mathrm{~mm}$ ) and more flaky particles than gabbro aggregate, but within the maximum specified limit of $2 \%$. Gabbro exhibited a higher particle density, lower water absorption 
and higher resistance to abrasion than Wadi gravel. Both aggregates showed high resistance to weathering, as determined from the soundness results, with gabbro exhibiting higher durability than Wadi gravel. Acid soluble chloride and sulfate requirements were also met, with higher values for the Wadi gravel aggregate compared with the gabbro aggregate.

Table 3 also provides the properties of the fine aggregate. The washed sand complied with the QCS 2014 requirements, with the exception of sulfate content. The acid-soluble sulfate was $0.6 \%$, exceeding the maximum permissible limit of $0.4 \%$.

Table 3 Properties of fine and coarse aggregates used for the trials.

\begin{tabular}{|c|c|c|c|c|c|}
\hline \multirow[b]{2}{*}{ Property } & \multicolumn{2}{|c|}{ Coarse Aggregate } & \multirow[b]{2}{*}{ Wadi gravel } & \multicolumn{2}{|c|}{ Fine Aggregate } \\
\hline & QCS limit & Gabbro & & QCS limit & $\begin{array}{l}\text { Washed } \\
\text { sand }\end{array}$ \\
\hline Fines content $(<63 \mu \mathrm{m}), \%$ & $2 \% \operatorname{Max}$ & 1.0 & 1.5 & $3 \% \operatorname{Max}$ & 1.0 \\
\hline Flakiness index, \% & $35 \% \operatorname{Max}$ & 7.0 & 14.0 & NA & NA \\
\hline Clay lumps and friable, $\%$ & $2 \% \operatorname{Max}$ & 0.15 & 0.33 & $2 \% \operatorname{Max}$ & 0.42 \\
\hline Lightweight pieces, \% & $0.5 \% \operatorname{Max}$ & 0.1 & 0.2 & $0.5 \% \operatorname{Max}$ & $<0.1$ \\
\hline Shell Content, \% & $3 \%$ Max & Nil & Nil & $3 \% \operatorname{Max}$ & Nil \\
\hline Los Angeles, \% & $30 \% \operatorname{Max}$ & 15 & 27 & NA & NA \\
\hline Particle density (Apparent) & $2.0 \mathrm{Min}$ & 2.93 & 2.70 & $2.0 \mathrm{Min}$ & 2.66 \\
\hline Water absorption, \% & $2 \% \operatorname{Max}$ & 0.43 & 1.08 & $2.3 \% \operatorname{Max}$ & 1.30 \\
\hline Soundness $\left(\mathrm{MgSO}_{4}\right), \%$ loss & 15\% Max & 3 & 7 & $15 \% \operatorname{Max}$ & 3.1 \\
\hline Acid-soluble chlorides, \% Cl- & $0.04 \% \operatorname{Max}$ & 0.01 & 0.02 & 006\% Max & 0.02 \\
\hline Acid-soluble sulfate, $\% \mathrm{SO}_{3}$ & $0.3 \% \mathrm{Max}$ & 0.1 & 0.2 & 0.4\% Max & 0.6 \\
\hline
\end{tabular}

\subsection{ASR Alkali-Reactivity Potential of Wadi Gravel-Laboratory Investigation}

\subsubsection{Petrographic Examination}

The petrographic examinations of the processed Wadi gravel identified five rock constituent types, which together accounted for at least $95 \%$ of the Wadi gravel. The gypsum-bound deposits (GBD), which accounted for about $20 \%$ of the raw Wadi gravel [9], were reduced to less than $1 \%$ by the intensive multi-stage processing. When the GBD are excluded, about half the gravel consists of limestone. The other half is a mixture of igneous and metamorphic rocks; comprising quartz (20\%), rhyolite $(9 \%)$, granite $(8 \%)$, and quartzite $(7 \%)$. In general, the petrographic examinations of the processed Wadi gravel found the aggregate combination to have 'low' to 'normal' alkali-silica reactivity in relation to the UK guidance given in BS 7943 [21] and BRE Digest 330 [22]. None of the constituents examined could be regarded as having 'high' reactivity.

\subsubsection{Expansion Tests}

Details of the expansion results are given elsewhere [9]. The $100 \%$ gabbro and $50 \%$ Wadi gravel mortars exhibited relatively low expansion values and fell into the innocuous category of ASTM C1260 after 14 days immersion (16 days age). The 100\% Wadi gravel mortar were marginally within 
the innocuous behaviour category of ASTM C1260. The main difference was found from the concrete prism expansion tests.

The RILEM AAR-4.1 concrete prism tests indicated that there could potentially be deleterious expansion with the $100 \%$ Wadi gravel mixture, but not with the $50 \%$ Wadi gravel mixture, which was non-expansive and very similar to the $100 \%$ gabbro mixture. The BS $812-123$ concrete prism test, Figure 7, which is more representative of field conditions, indicated that both the $100 \%$ and $50 \%$ Wadi gravel mixtures were non-expansive, despite the presence of some potentially expansive rock types in the gravel. The long-term performance of the trial buildings will therefore help to establish whether the $100 \%$ Wadi gravel concrete is liable to experience expansive reactions due to ASR or other causes.

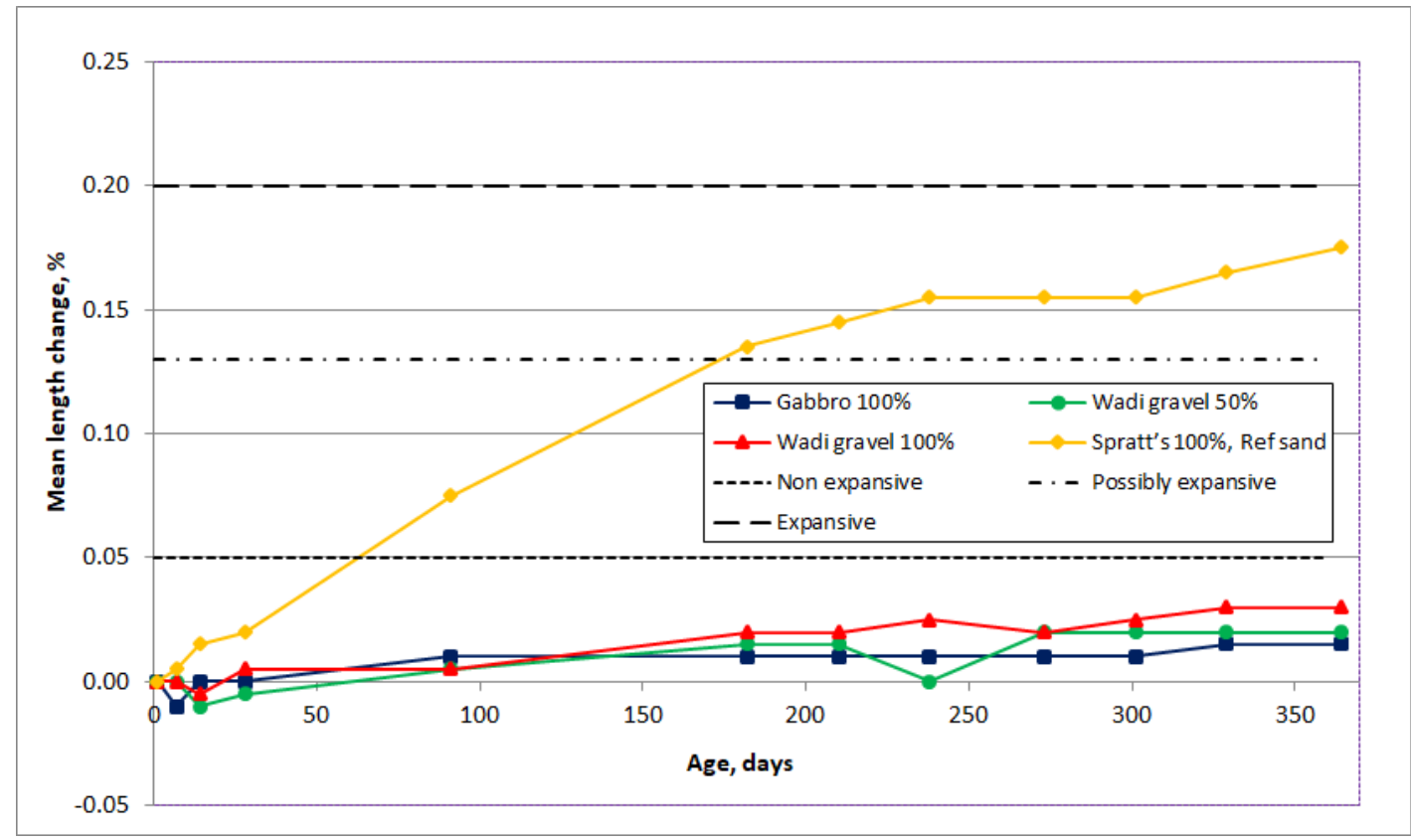

Figure 7 BS 812-123:1999 expansion of concrete prisms (modified from Hassan et al., 2020).

\subsection{Performance of Concrete in Building Trials}

\subsubsection{Variation of Concrete Batches}

The slump and compressive strength testing were used to assess the variation of concrete batches delivered to site, and the results are presented in Table 4. A target slump of $100 \mathrm{~mm}$ minimum was set on arrival at site to enable easy pumping and compacting of the concrete mixtures. The slump values ranged from 150 to $220 \mathrm{~mm}$, with the majority of results being between 180 and $200 \mathrm{~mm}$. The slump results for the delivered concrete were generally higher than the desired target of $100 \mathrm{~mm}$.

Table 4 Slump ( $\mathrm{mm}$ ) and compressive strength (MPa) results of concrete batches.

\begin{tabular}{|c|c|c|c|c|c|c|c|c|c|}
\hline \multirow[t]{2}{*}{ Concrete } & \multicolumn{3}{|c|}{ 100\% Gabbro } & \multicolumn{3}{|c|}{$50 \%$ Wadi gravel } & \multicolumn{3}{|c|}{$100 \%$ Wadi gravel } \\
\hline & Slump & $7 d$ & $28 d$ & Slump & $7 d$ & $28 d$ & Slump & $7 d$ & $28 d$ \\
\hline
\end{tabular}




\begin{tabular}{|c|c|c|c|c|c|c|c|c|c|}
\hline Foundations & 200 & 53.3 & 65.3 & 190 & 50.9 & 62.1 & 180 & 46.9 & 57.1 \\
\hline Ground beams & 210 & 40.8 & 55.9 & 220 & 41.9 & 53.7 & 200 & 40.1 & 50.8 \\
\hline $\begin{array}{l}\text { Columns/control } \\
\text { beams }\end{array}$ & 190 & 45.4 & 54.9 & 200 & 45.5 & 51.9 & 200 & 43.2 & 50.8 \\
\hline Roof slabs & 190 & 48.2 & 57.6 & 180 & 46.6 & 54.8 & 150 & 45.1 & 53.1 \\
\hline Average & & 46.9 & 58.4 & & 46.2 & 55.6 & & 43.8 & 53.0 \\
\hline CV\% & & 11.1 & 8.1 & & 8.0 & 8.1 & & $6.6 \%$ & 5.6 \\
\hline
\end{tabular}

The cube compressive strengths at 7 and 28 days are also given in Table 4 . At 28 days, the mixtures exceeded the desired strength of $\mathrm{C} 40$ concrete and achieved values in excess of $50 \mathrm{MPa}$. The $100 \%$ gabbro concrete exhibited the highest strength of $58.4 \mathrm{MPa}$ at 28 days, and the lowest of 53.0 MPa was obtained for the $100 \%$ Wadi gravel concrete. In fact, the mixtures achieved the target C40 after 7 days in cube tests, with average values of $46.9 \mathrm{MPa}$ for the $100 \%$ gabbro, 46.2 for the $50 \%$ Wadi gravel, and a slightly lower average of $43.8 \mathrm{MPa}$ for the $100 \%$ Wadi gravel. The variation of compressive strength results for the different batches ranged between $6 \%$ and $11 \%$, indicating a good quality of concrete production.

\subsubsection{Moisture and Salt Contents}

During construction, soil samples, from excavated materials, were collected and tested for chloride and sulfate contents as per BS 1377-3 [19]. For earth works related to buildings, the QCS 2014 specifies maximum values of acid soluble chloride not exceeding $2 \%$, and $3 \%$ for acid soluble sulfate. The soil testing indicated sulfate content of $2.58 \%$, which is relatively high, but within the maximum permitted level. Much lower chloride content of $0.04 \%$ was measured in the surrounding soil. Concrete cores were extracted after 4 years from the test beams. Cores were tested for wet density, moisture content, chloride content and sulfate content, and the results are presented in Table 5.

Table 5 Density, moisture content and salt contents at 4 years.

\begin{tabular}{llll}
\hline Material & $100 \%$ Gabbro & $50 \%$ Wadi gravel & $100 \%$ Wadi gravel \\
\hline Density, $\mathrm{kg} / \mathrm{m}^{3}$ & 2347 & 2310 & 2250 \\
Moisture content, \% & 3.7 & 3.8 & 3.3 \\
Acid-soluble chlorides, \% $\mathrm{Cl}-$ & 0.01 & 0.01 & 0.01 \\
Acid-soluble sulfate, $\% \mathrm{SO}_{3}$ & 0.61 & 0.83 & 1.12 \\
\hline
\end{tabular}

The gabbro aggregate, with its high particle density, gave the highest concrete density of 2347 $\mathrm{kg} / \mathrm{m}^{3}$. Substituting the gabbro with $100 \%$ Wadi gravel reduced the concrete density to $2250 \mathrm{~kg} / \mathrm{m}^{3}$. The $50 \%$ Wadi gravel concrete gave an intermediate value of $2310 \mathrm{~kg} / \mathrm{m}^{3}$. The moisture content ranged between $3.3 \%$ and $3.8 \%$ for the different concrete mixtures. The amounts of acid-soluble chloride measured were identical and negligible. The sulfate content was much higher, with the highest value of $1.12 \%$ for the $100 \%$ Wadi gravel, and the lowest of 0.61 for the $100 \%$ gabbro. 


\subsubsection{Concrete Strength and Absorption}

Cores were taken from the test beams after 28 days, one year and four years. The core compressive strength results are presented graphically in Figure 8. Three cores were tested for each building and age, and the coefficient of variation ranged between $3.0 \%$ and $10.6 \%$. The range of variation is considered to be low, considering the inferior repeatability of core strength to that of standard cast specimens [17]. Similar to the original cube results, all the mixtures achieved the target C40 strength. The $100 \%$ gabbro concrete exhibited the highest strength of $45.2 \mathrm{MPa}$, with slightly lower average values of $41.7 \mathrm{MPa}$ and $41.3 \mathrm{MPa}$ for the $50 \%$ and $100 \%$ Wadi gravel concretes, respectively. Strength development continued with age up to 4 years in service to reach $57.6 \mathrm{MPa}$, 53.1 MPa and 52.2 MPa for the 100\% gabbro, 50\% Wadi gravel, and the 100\% Wadi gravel, respectively.

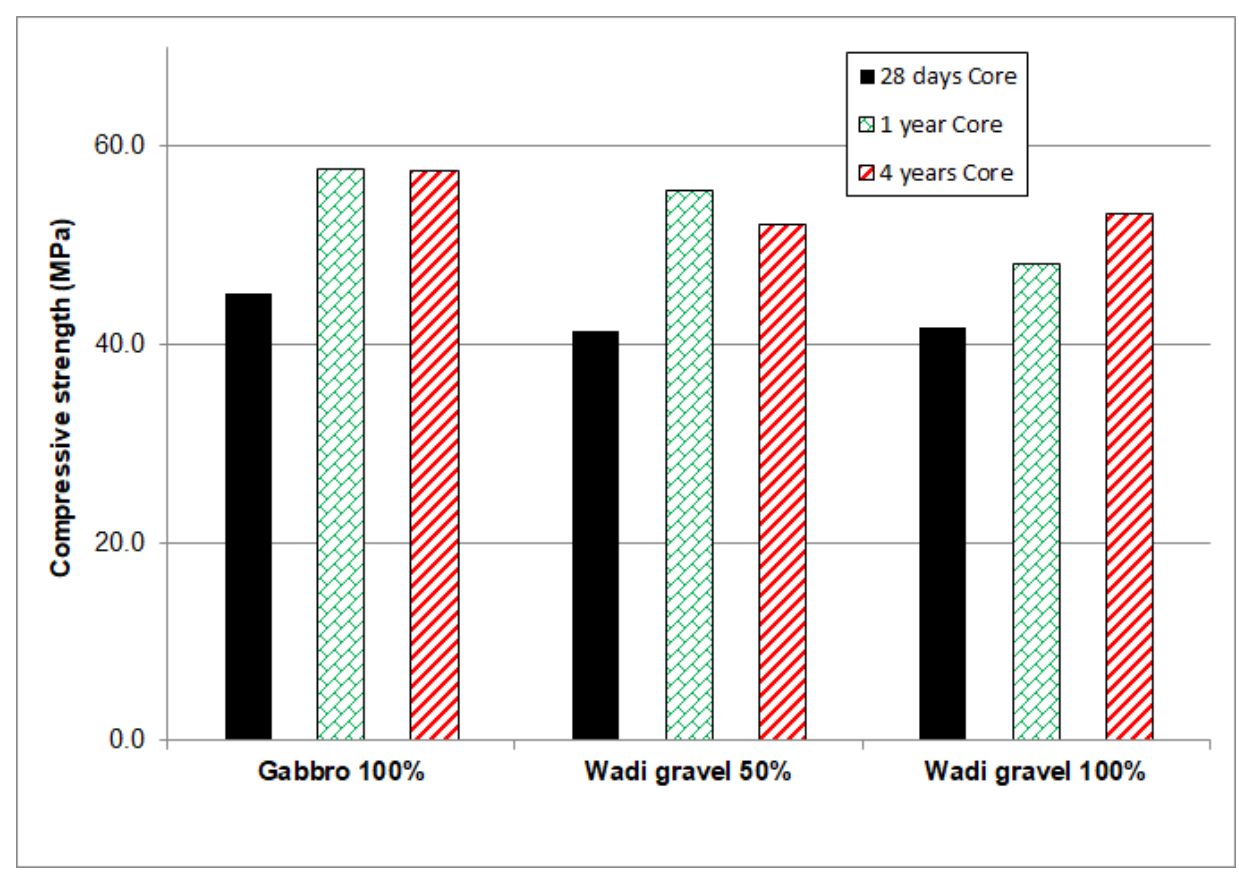

Figure 8 Core compressive strength of Wadi gravel and gabbro concrete mixtures.

The water absorption results are presented in Figure 9. All the mixtures showed low porosity values within the range of $1 \%$ to $2 \%$ at the different ages up to 4 years in service. The absorption results are lower than the range recommended in the QCS 2014 of 2\% - 4\% for durable concrete. The absorption results followed the same trend as the strength results, with slightly lower absorption results of the gabbro concrete compared with the Wadi gravel concrete at 28 days and after 4 years. After 1 year, the values were almost identical for all three mixtures. 


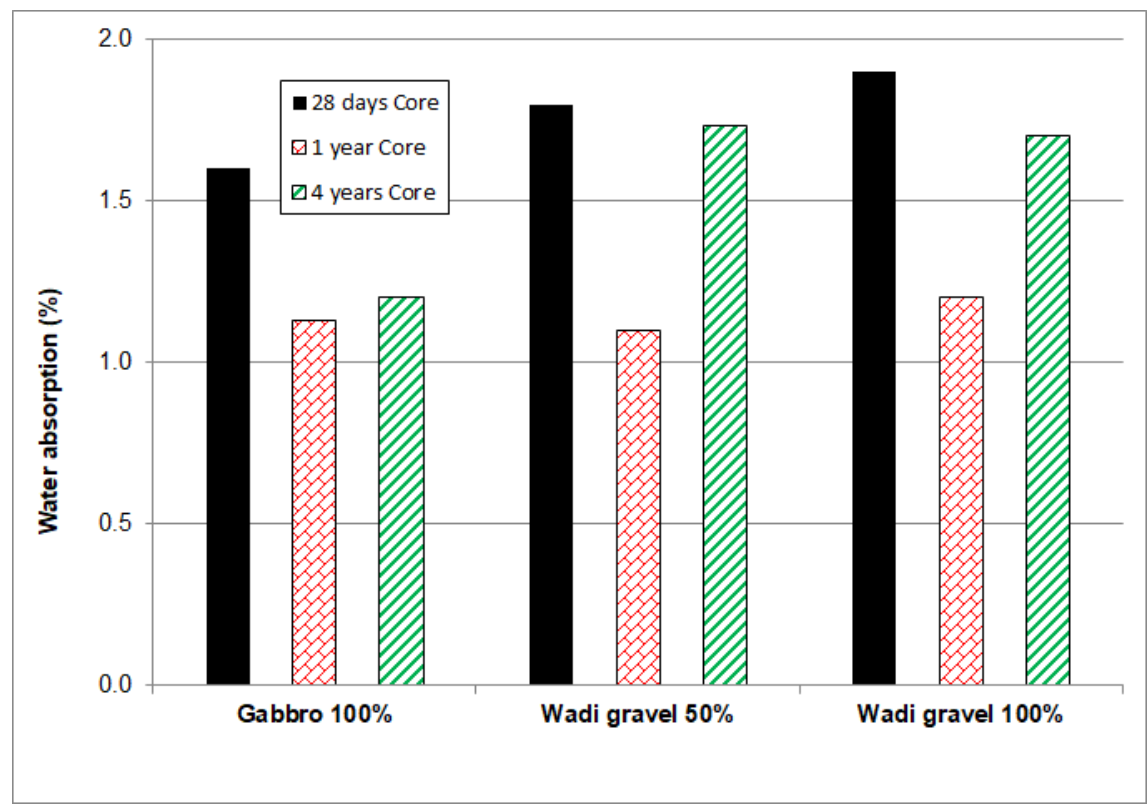

Figure 9 Core water absorption of Wadi gravel and gabbro concrete mixtures.

\subsubsection{Petrographic Examination of Concrete Cores after 4 Years}

The cores extracted from test beams after 4 years were examined petrographically to assess any evidence of ASR. This analysis relies on the expertise of the petrographer and comparison with known parameters for structural concrete. The following section simply summarises the concrete petrography test results (Table 6), with particular emphasis on ASR.

Table 6 Summary of petrographic examination of concrete cores after 4 years.

\begin{tabular}{llll}
\hline Parameter & $100 \%$ Gabbro & $50 \%$ Wadi gravel & 100\% Wadi gravel \\
\hline Mix quality & Good compaction & Good compaction & Good compaction \\
Air voidage, \% & $2.0-3.0$ & $2.0-3.0$ & $3.0-4.0$ \\
ASR & No evidence & No evidence & No evidence \\
Cracking/Microcracking & No evidence & No evidence & No evidence \\
Deposits & Trace ettringite & Trace ettringite & Trace ettringite \\
\hline
\end{tabular}

Across all mixes, the cores exhibit a dense well compacted concrete (Figure 10) with evenly distributed air voids and no significant cracking or significant levels of secondary deposits. These observations indicate no significant deterioration and/or distress within or differential behaviour observed between concrete utilising Wadi gravel and that containing imported Gabbro. 


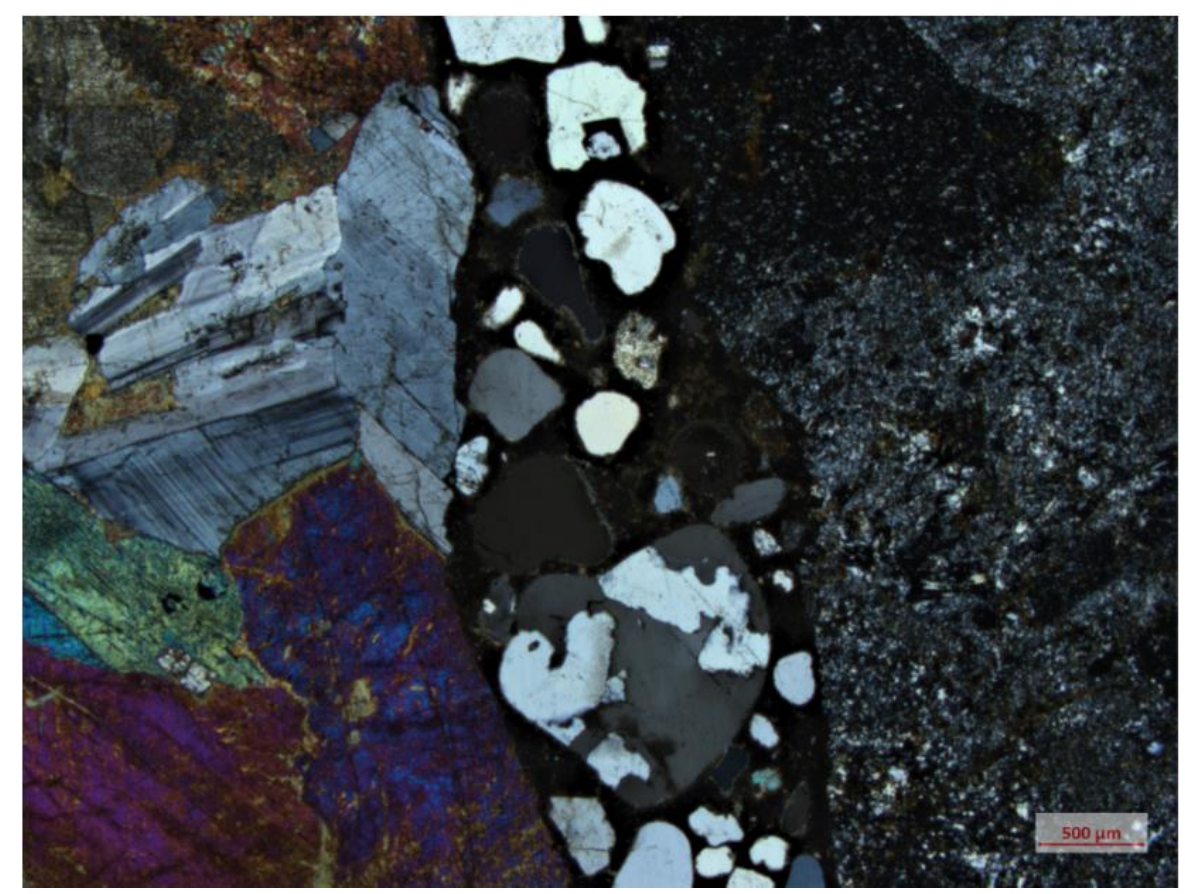

Figure 10 Microscopical images of gabbro (left) and rhyolite (right) in 50\% Wadi gravel concrete.

The petrographic examination allows assessment for evidence of ASR by the observation of any diagnostic features present within the core. These include ASR reaction sites or products, such as silica gel, and evidence of any micro-cracking associated with aggregate-binder interfaces. None of these features were observed within the cores or thin sections observed, inferring that no observable ASR had occurred within any of the cores. The lack of deleterious reactions can be seen within Figure 11, Figure 12, Figure 13 and Figure 14, wherein the micro/cryptocrystalline silica within rhyolite (Figure 10 \& Figure 13), and quartzite (Figure12 \& Figure 14) exhibit no ASR sites or associated silica gel.

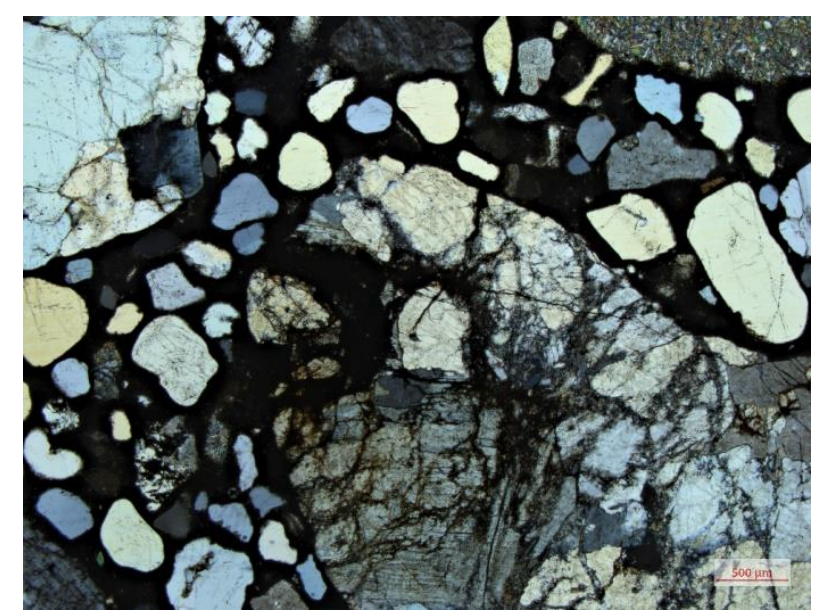

Figure 11 Granite rock-50\% Wadi gravel. 


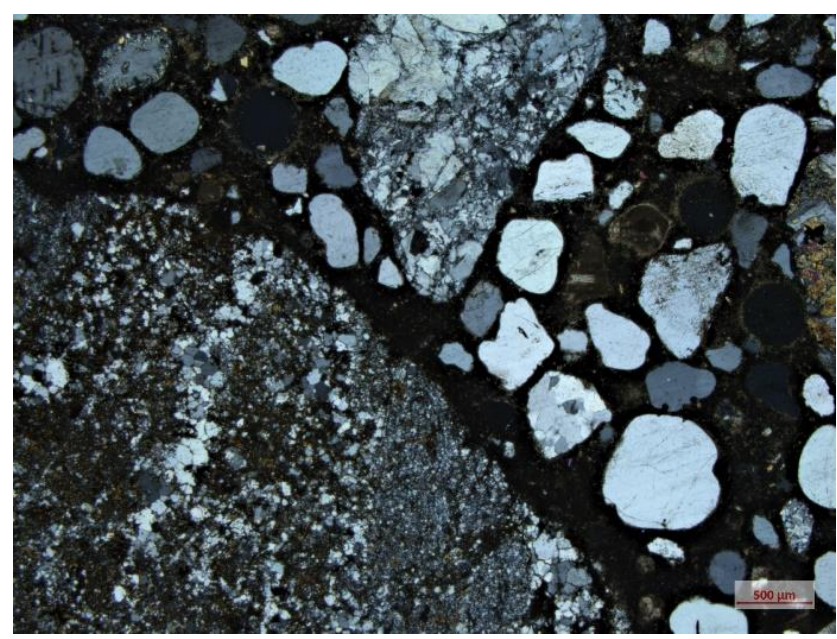

Figure 12 Quartzite rock-50\% Wadi gravel.

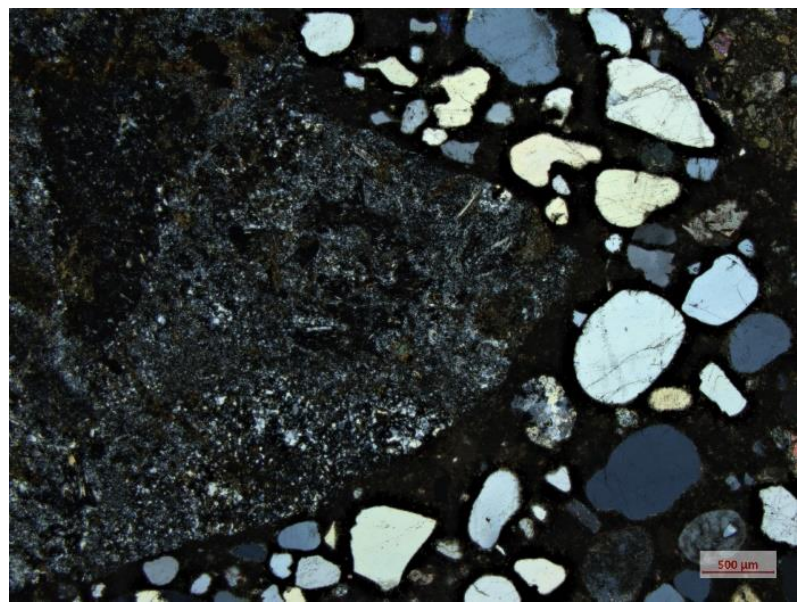

Figure 13 Rhyolite rock-50\% Wadi gravel.

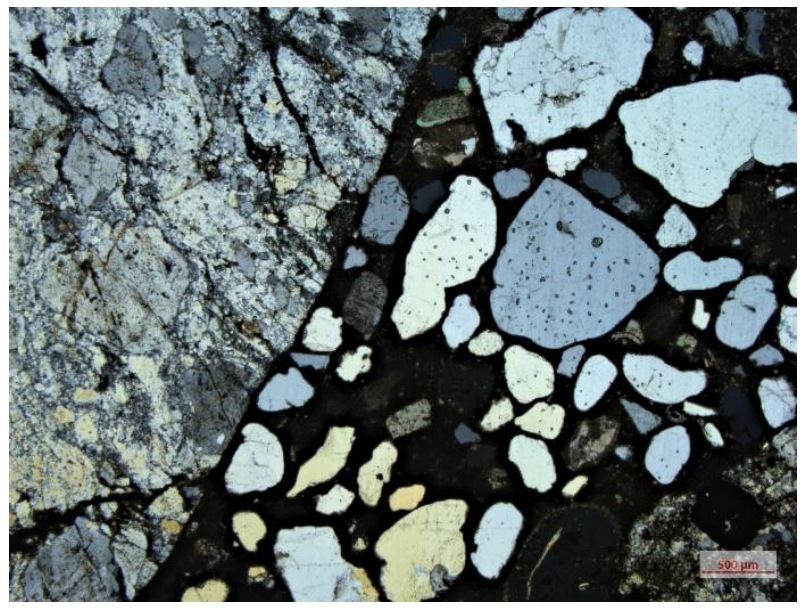

Figure 14 Quartzite rock-100\% Wadi gravel.

All the mixes exhibited a consistent Portland-cement matrix without significant evidence of alteration. The concretes all appeared generally sound with only minor evidence of leaching remobilising sulfate, giving rise to secondary ettringite deposits (Figure 15) that were too limited to 
be indicative of damaging sulfate attack. The petrographic examination after 4 years supports the BS 812-123 finding of low alkali-silica reactivity of Wadi gravel.

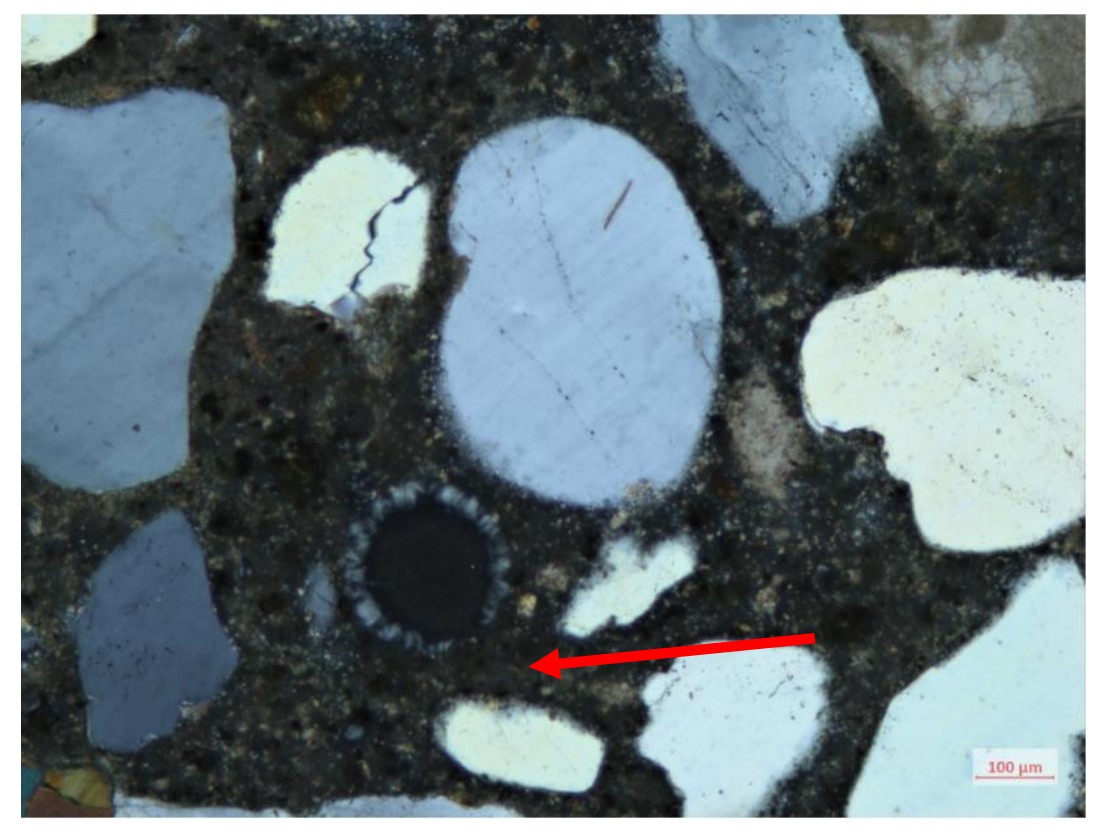

Figure 15 Small air void lined by ettringite in $100 \%$ gabbro concrete (shown by the arrow).

\section{Discussion}

The use of Wadi gravel in Qatar is still rather limited, mainly due to the perceived risk of alkaliaggregate reactivity (AAR) and sulfate attack, with lack of long-term performance data to provide confidence in use.

Petrographic examinations have been conducted on the hardened concrete mixtures after 4 years in service to assess potential ASR, and to clarify the different expansion behaviours for the different concrete prism tests. The results indicated sound concrete with no observed cracking or microcracking, and no evidence of distress or deterioration from ASR or sulfate attack. The 4-year petrographic results of the hardened concrete support the results obtained from the BS 812-123 expansion test and indicate that the Wadi gravel could be classified as a non-expansive aggregate. Based on the results obtained in this study, the BS 812-123 method is considered ultimately more representative of performance in practice than the accelerated RILEM AAR-4.1 method.

The trial buildings were visually inspected periodically up to 4 years in service. The 3 buildings looked generally identical, with no obvious differences between them (Figure 16). The climate in Qatar is generally hot and humid during summer, with some strong storms and heavy rains in winter. Despite these harsh weather conditions, the buildings remained in good condition, with no visual signs of deterioration. No structural damage was apparent, Figure 16. 


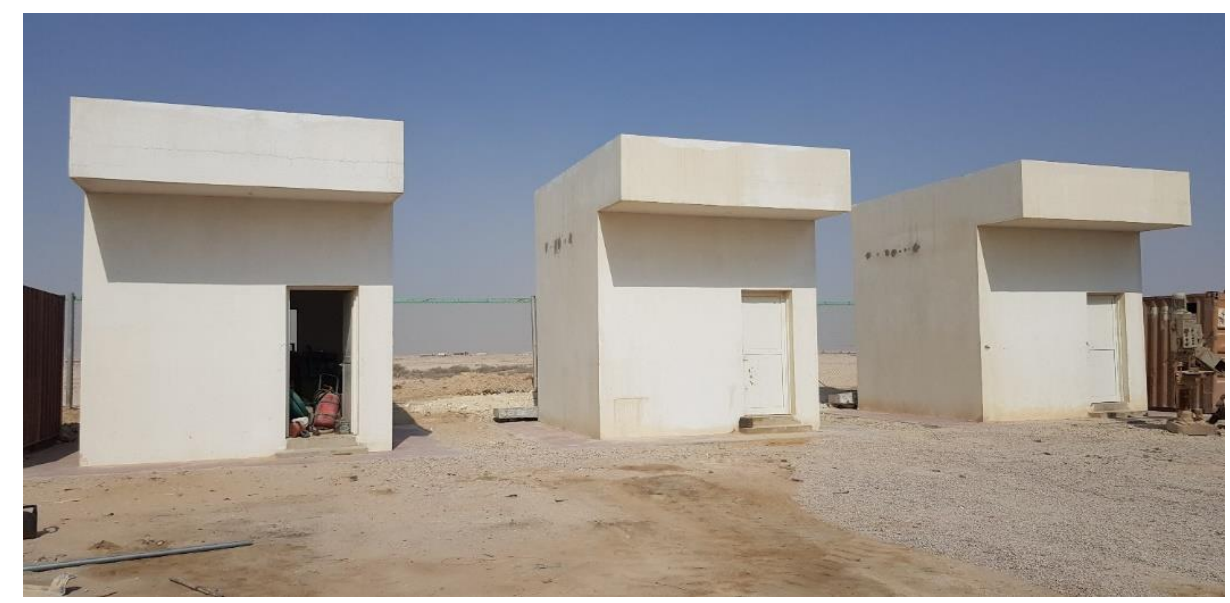

Figure 16 Trial buildings, 4 years after construction: control (100\%) gabbro on left; $50 \%$ Wadi gravel in centre; $100 \%$ Wadi gravel on right.

Core samples were obtained from the test beams, stored behind the building trials. The core strength achieved the target $\mathrm{C} 40$ concrete at 28 days. Strength development continued, with the availability of moisture within the pore structure of concrete, as confirmed by the moisture content results. The water absorption results were lower than $2 \%$ for the different mixtures at all tested ages up to 4 years. The QCS 2014 recommends a range of 2-4\% water absorption as an indication of durable concrete. The absorption results obtained in this study for the Wadi gravel and gabbro aggregates were lower than the minimum level recommended, and hence would be expected to provide high resistance to the ingress of harmful substances into concrete.

The trial beams were exposed to the most aggressive environment within the trials. They were partially buried in a soil with a relatively high sulfate content and also exposed to the diurnal heat cycles at the surface. The trial beams have also been more at risk of deterioration, owing to periodic exposure to moisture in the soil during rainy periods. In this inland site, the groundwater table is well below the surface, but in coastal areas foundation concrete would also be exposed to potential capillary rise of salts from ground water. The availability of moisture and heat would potentially accelerate the deterioration mechanisms of sulfate attack and ASR. The tight pore structure and low absorption values have contributed to mitigate the risk of sulfate attack of concrete.

The relatively high sulfate content of all mixtures may be attributed to the washed sand, which contained high levels of $0.6 \%$ sulfate content, and exceeded the maximum permitted limit in the QCS 2014. The Wadi gravel aggregate has also contributed to the combined sulfate content of concrete. Whilst the Wadi gravel met with the sulfate requirement of the QS 2014, its value was double that of gabbro aggregate (Table 2). The trend of increased sulfate content for higher contents of Wadi gravel in the concrete mixture is therefore to be expected. At the highest level of Wadi gravel (100\%), the total acid-soluble sulfate was measured as $1.12 \%$; however, this had not caused any cracking within the concrete matrix. Petrographic examination of hardened concrete after 4 years detected only traces of white sulfate deposits (ettringite) lining the air voids of concrete, with no evidence of other distress or deterioration due to sulfate attack. On-going testing is planned for the building trials and partially buried beams to assess longer-term performance and correlated to laboratory accelerated testing.

Wadi gravel offers a quality aggregate for use in concrete and is available locally in Qatar and other parts of the Gulf region. When the material is processed properly to meet with the QCS 2014 
requirements, particularly sulfate content, it has the potential to replace up to $100 \%$ of imported gabbro in structural concrete applications. This has important implications for the use of Wadi gravel in concrete, as it is easier - and cheaper - to make concrete with one aggregate rather than a blend of two or more types of aggregate, such as the 50:50 blend with gabbro used in this study. Site testing after 4 years in service showed similar performance to the conventional gabbro concrete. The results obtained in this study also support the finding of the BS 812-123 test for Wadi gravel to be classified as having low reactivity in relation to AAR and confirms that the BS 812-123 test is more representative of the behaviour of concrete in the field than the RILEM AAR 4.1 concrete prism test or the ASTM C1260 mortar bar test.

\section{Conclusions}

The paper presents the results of 4 years' site performance of concrete made using Wadi gravel aggregate and builds on initial data presented for laboratory tests and up to 1-year field performance, when Wadi gravel is used to replace $50 \%$ and $100 \%$ of conventional gabbro in structural concretve. Intensive multistage processing of Wadi gravel has successfully produced compliant aggregate and reduced the sulfate content to acceptable levels for use in structural and non-structural concretes.

The laboratory investigation for assessing the potential AAR of Wadi gravel was conducted in different phases. For the concrete prism methods, Wadi gravel was classified as potentially reactive in the RILEM AAR-4.1 and of low reactivity in the BS 812-123 test. The BS 812-123 interpretation was confirmed by petrographic examination of the hardened concrete after 4 years in service, as no signs of AAR or cracking were detected in the Wadi gravel concrete.

The three full scale trial buildings have demonstrated that Wadi gravel can be used to replace $50 \%$ and $100 \%$ of imported gabbro, with at least similar performance to the $100 \%$ gabbro concrete. Wadi gravel was easily implemented in the ready-mix concrete plant for the production of structural concrete within the hot summer of Qatar, and to the desired temperature control and workability. At the same $w / c$ ratio, Wadi gravel concrete requires less superplasticiser dosage to achieve the same workability as the gabbro concrete. The target C40 concrete compressive strength was achieved after 28 days, with continuous strength development to over $50 \mathrm{MPa}$ after 4 years and with water absorption of below $2 \%$.

The test beams, used for the assessment of site performance of Wadi gravel concrete, were exposed to the most aggressive environment within the trials. They were partially buried and surrounded by soil with a relatively high sulfate content, and exposed to heat cycles on the surface and potential moisture from rainy periods and capillary rise. Despite the aggressive exposure environment, the Wadi gravel concrete exhibited sound performance, similar to that of gabbro concrete, with no observed cracking or defects on the buildings, and no evidence of distress or deterioration from ASR or sulfate attack within the concrete microstructure.

It is important to stress that if Wadi gravel is used as aggregate in concrete, it must be produced under a quality control system that ensures it is subject to rigorous processing to remove the gypsum-bound material and reduce the sulfate content to acceptable levels, as described in Hassan et al. [7]. If excessive quantities of gypsum-bound deposits are somehow included in the concrete, the resulting expansive reactions will likely result in poor quality concrete, which will deteriorate rapidly and bring the material into disrepute. 
Based on the outcomes of this work, Wadi gravel is currently permitted for use in structural and non-structural concrete at levels of up to $100 \%$ of the coarse aggregate in the Ashghal Recycling Manual 2021 [23]. The Public Works Authority (Ashghal) also requires that the aggregate is processed in accordance with the methods set out in Hassan et al. [7] or similar and meets the requirements of the Qatar Construction Specifications. Further monitoring of the trial buildings will be carried out to confirm the long-term behaviour of the Wadi gravel concrete mixtures.

\section{Acknowledgments}

The authors are grateful to the Qatar Ministry of Municipality and the Public Works Authority for their constructive support and dissemination of the outcomes.

\section{Author Contributions}

Khaled Hassan: Site construction and testing; Performance results and discussion; Writing original draft. Ian Sims: Concept and methodology of ASR investigation; Review of results and manuscript edits. Murray Reid: Geology of Qatar; Properties of Wadi gravel aggregate; Writing and edits. Alex Smith: Supervision of petrographic and expansion testing; Data analysis; Writing and editing. Mohammed Al-Kuwari: Coordination of site work, Review of manuscript.

\section{Funding}

The work for the 4 year investigation was funded by Qatar National Research Fund, National Priority Research Programme, project no. NPRP7-795-2-296.

\section{Competing Interests}

The authors have declared that no competing interests exist.

\section{References}

1. Planning and Statistics Authority. Qatar National Vision 2030 [Internet]. Doha: Government of the State of Qatar, Planning and Statistics Authority; 2008. Available from: https://www.psa.gov.qa/en/qnv1/pages/default.aspx.

2. Fookes PG. Concrete in the middle east-past, present and future: A brief review. Concrete. 1993; 27: 14-20.

3. Fookes PG, Lee EM. The engineering geology of concrete in hot drylands. Q J Eng Geol Hydrogeol. 2019; 52: 257-279.

4. Walker MJ. Hot deserts: Engineering, geology and geomorphology. London: The Geological Society; 2012.

5. Leblanc J. A fossil hunting guide to the tertiary formations of Qatar, Middle East. 1st ed [Internet]. $2008 . \quad$ Available from. https://www.researchgate.net/publication/280042253 A fossil hunting guide to the Terti ary formations of Qatar 2008.

6. Hassan KE, Reid JM, MS Al-Kuwari. Use of recycled and secondary aggregates in Qatar: Guidance document. Crowthorne: TRL Ltd; 2015; PPR736. 
7. Hassan K, Reid M, Sims I, bin Saif Al-Kuwari M, Attia M, Sediq A, et al. Wadi gravel-a new concrete aggregate in Qatar: Part 1-investigation, processing and trials. Q J Eng Geol Hydrogeol. 2020; 53: 386-399.

8. Qatar Standards. Qatar Construction Specifications [Internet]. Doha: Ministry of Municipality \& Environment; $2014 . \quad$ Available from: http://www.mme.gov.qa/cui/view.dox?id=1441\&contentID=3815\&sitelD=2.

9. Sims I, Hassan K, Reid M, bin Saif Al-Kuwari M, Attia M, Sidiq A, et al. Wadi gravel-a new concrete aggregate in Qatar: Part 2-Alkali aggregate reactivity. Q J Eng Geol Hydrogeol. 2020; 53: 400412.

10. British Standards. Cement-composition, specifications and conformity criteria for common cements. London: BSI; 2011; BS EN 197-1: 2011.

11. British Standards. Testing fresh concrete. Slump test. London: BSI; 2019; BS EN 12350-2: 2019.

12. British Standards. Testing aggregates. Method for qualitative and quantitative petrographic examination of aggregates. London: BSI; 1994; BS 812-104: 1994.

13. ASTM International. Standard test method for potential alkali reactivity of aggregates (mortarbar method). West Conshohocken: ASTM International; 2014; ASTM C1260-14.

14. RILEM. Recommended Test Method for the detection of potential alkali-reactivity- $60{ }^{\circ} \mathrm{C}$ test method for aggregate combinations using concrete prisms. Paris: RILEM; 2015; RILEM AAR-4.1: 2015.

15. British Standards. Method for determination of alkali-silica reactivity-concrete prism method. London: BSI; 1999; BS 812-123: 1999.

16. British Standards. Testing hardened concrete. Compressive strength of test specimens. London: BSI; 2019; BS EN 12390-3: 2019.

17. British Standards. Testing concrete in structures. Cored specimens. Taking, examining and testing in compression. London: BSI; 2019; BS EN 12504-1: 2019.

18. British Standards. Testing concrete. Method for determination of water absorption. London: BSI; 2011; BS 1881-122:2011.

19. British Standards. Methods of test for soils for civil engineering purposes. Chemical and electrochemical testing. London: BSI; 1990; BS 1377-3: 1990.

20. ASTM International. Standard practice for petrographic examination of hardened concrete. West Conshohocken: ASTM International; 2018; ASTM C856-18.

21. British Standards. Guide to the interpretation of petrographical examinations for alkali-silica reactivity. London: BSI; London; 1999; BS 7943: 1999.

22. BRE. Alkali-silica reaction in concrete. Watford: Building Research Establishment; 2004; BRE Digest 330: 2004.

23. Ashghal Center for Research and Development. Ashghal Recycling Manual. Doha: Ashghal Public Works Authority; 2021. 


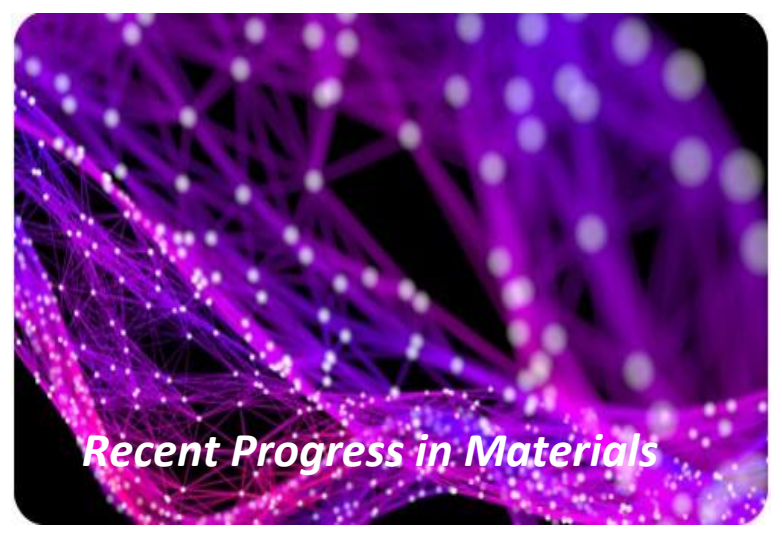

Enjoy Recent Progress in Materials by:

1. Submitting a manuscript

2. Joining in volunteer reviewer bank

3. Joining Editorial Board

4. Guest editing a special issue

For more details, please visit:

http://www.lidsen.com/journals/rpm 